\section{Category}

Metal-Catalyzed Asymmetric

Synthesis and

Stereoselective

Reactions

\section{Key Words}

asymmetric

catalysis

C-H activation

chiral auxiliaries

iodine

palladium

R. GIRI, X. CHEN, J.-Q. YU* (BRANDEIS UNIVERSITY, USA)

Palladium-Catalyzed Asymmetric Iodination of Unactivated C-H Bonds under Mild Conditions

Angew. Chem. Int. Ed. 2005, 44, 2112-2115.

\title{
Pd-Catalyzed Diastereoselective lodination of Unactivated C-H Bonds
}
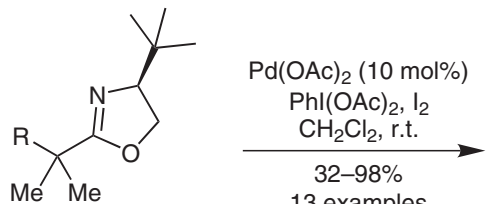

13 examples

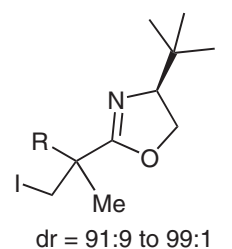

Significance: Palladium-catalyzed functionalization of an unactivated $\mathrm{C}-\mathrm{H}$ bond $\beta$ to a functional group oxazoline was achieved. The tert-butyl oxazoline auxiliary gave highly diastereoselective functionization of diastereotropic $\mathrm{C}-\mathrm{H}$ bonds. The substrates can be easily prepared from their corresponding carboxylic acid and readily available (S)-tert-leucinol.
Comments: $\mathrm{C}-\mathrm{H}$ bond activation by cyclometallation of palladium is well known as a stoichiometric process. The authors chose a chelating chiral oxazoline auxiliary to favor catalyst turnover affording synthetically useful iodides in generally good to excellent yield. The Pd catalyst can be easily reused many times. Excellent diastereoselectivity was obtained by using enantiopure tert-butyl oxazoline, which can be cleaved using $\mathrm{H}_{2} \mathrm{SO}_{4}$ /dioxane to afford an enantioenriched carboxylic acid (up to $99 \%$ ee). The $\mathrm{C}-\mathrm{H}$ functionalization reaction also takes place preferentially on activated bonds such as cylcopropyl C-H or ortho-aromatic $\mathrm{C}-\mathrm{H}$ bonds, further increasing the utility of the process. 